\title{
Use of refuges by the ophiuroid Ophiopholis aculeata: contrasting effects of substratum complexity on predation risk from two predators
}

\author{
David Drolet ${ }^{1}$, John H. Himmelman ${ }^{1, *}$, Rémy Rochette ${ }^{2}$ \\ ${ }^{1}$ Département de Biologie and Québec-Océan, Université Laval, Québec GIK 7P4, Canada \\ ${ }^{2}$ Biology Department, University of New Brunswick, Saint John, New Brunswick E2L 4L5, Canada
}

\begin{abstract}
We investigated the effect of substratum complexity on the vulnerability of the ophiuroid Ophiopholis aculeata to its 2 main predators, the sea star Asterias vulgaris (possibly synonymous with A. rubens) and the urchin Strongylocentrotus droebachiensis, and further examined behavioral responses of ophiuroids to these predators. Field and laboratory experiments showed that the use of crevices by ophiuroids tended to reduce predation by urchins. The ophiuroids' response to contact with the urchin was to retract deeper into crevices. In contrast, in the laboratory, the ophiuroids' vulnerability to the sea star was higher on complex substrata. In the laboratory, ophiuroids reacted weakly to contact with the arm tip or ambulacral groove of A. vulgaris, but immediately fled refuges when there was contact with the sea star's stomach. In the field, the density of ophiuroids in $20 \mathrm{~cm}$ diameter circular plots placed around sea stars (both feeding and non-feeding) was similar to that in areas without sea stars. However, the estimated density of ophiuroids directly under sea stars was less than in areas without sea stars, and exposed ophiuroids (with the disk outside a crevice) were more abundant near $A$. vulgaris than in areas without sea stars: both differences were greater when the sea star was feeding. Ophiuroids display risk sensitivity adjusted to the 2 predators. They mainly flee crevices under a sea star when there is contact with the sea star's stomach, but only move a few centimeters. A last-moment departure should increase the probability of capture by sea stars, but reduces time spent on open surfaces where they are vulnerable to urchin attacks.
\end{abstract}

KEY WORDS: Predation $\cdot$ Trade-off $\cdot$ Habitat complexity $\cdot$ Refuge $\cdot$ Anti-predator behavior $\cdot$ Threat sensitivity $\cdot$ Echinoderms

\section{INTRODUCTION}

The structural complexity of habitats can affect aquatic communities by influencing recruitment (Lemire \& Bourget 1996, Walters \& Wethey 1996), distribution patterns (Steger 1987, Moran \& Reaka 1988) and species diversity (Eklov 1997). Use of complex habitats can also decrease exposure to environmental stress (Gosselin \& Chia 1995, Jones \& Boulding 1999). Many studies have shown that refuges associated with macrophytes (e.g. Johns \& Mann 1987, Russo 1987, Diehl 1988, Nelson \& Bonsdorff 1990, Kenyon et al. 1995, Moksnes et al. 1998, Stunz \& Minello 2001), corals (e.g. Beukers \& Jones 1997, Nemeth 1998) and bottom materials (e.g. Coull \& Wells 1983, Sponaugle \& Lawton 1990, Wahle \& Steneck 1992, Stunz \& Minello 2001, Wong \& Barbeau 2003) can reduce rates of predation. Structural components can either make the prey less visible (Main 1987) or enhance escape by slowing the movement of predators (Ryer 1988, Bartholomew et al. 2000) and permitting prey to stay out of their reach (Main 1987). The use of refuges is a good means of avoiding fast-moving, visual predators and can also reduce predation by slow-moving predators that locate prey using chemodetection (Levitan \& Genovese 1989, Arsenault \& Himmelman 1996, Wong \& 
Barbeau 2003). As a general rule, habitat complexity reduces predation but systems with ambush predators are an exception; in these cases habitat complexity may not affect, or may even increase, mortality from predation, as structural components reduce the capacity of prey to detect predators (James \& Heck 1994, Walsh 1995, Flynn \& Ritz 1999).

In addition to causing death, predators may also modify the behavior of their prey. Energetic costs are associated with behavioral responses, either directly when costly escape responses are deployed (Brokordt et al. 2003) or indirectly when foraging is reduced in situations of risk (Fraser \& Gilliam 1987, Bishop \& Brown 1992, Vadas et al. 1994, Behrens Yamada et al. 1998). To minimize such costs, prey often show threatsensitivity and adjust the intensity of their responses to the level of predatory threat (Helfman 1989, Legault \& Himmelman 1993). Prey species should adjust antipredator behaviors to minimize the ratio of costs (direct and indirect) and benefits (e.g. foraging or mating), thus maximizing fitness (Lima \& Dill 1990).

Ophiuroids are preyed upon by many organisms, including fishes (Keats et al. 1987, Witman \& Sebens 1992, Packer et al. 1994), decapod crustaceans (Wurzian 1977, Carter \& Steel 1982) and asteroids (Brun 1972, Gaymer et al. 2001a,b). They avoid encounter with predators by responding to chemical exudates from the predators (Feder \& Arvidsson 1967) or injured conspecifics (Rosenberg \& Selander 2000) and by hiding in refuges (Hendler 1984, Witman 1985). Once there has been contact with a predator, ophiuroids can avoid being eaten by using active flight (Feder \& Arvidsson 1967, Skold 1998), arm autotomy (Wilkie 1978), protective secretions (Fontaine 1964) and bioluminescence (which may function as aposematic coloration; Grober 1988a,b, Deheyn et al. 2000). Cryptic ophiuroids may also retreat deeper into refuges to stay out of reach of the predator (Solan \& Battle 2003)

In the subtidal community of the Mingan Islands in the northern Gulf of St. Lawrence (eastern Canada), the brittle star Ophiopholis aculeata occurs in dense populations (up to 1700 ind. $\mathrm{m}^{-2}$ ) on vertical walls, particularly in zones with strong tidal currents (Gaymer et al. 2001a). Most individuals keep their central disk tucked into crevices, under rocks and among coralline algae, and their arms are often extended to feed on suspended particles (see LaBarbera 1978). The green sea urchin Strongylocentrotus droebachiensis (this study) and the sea star Asterias vulgaris (Gaymer et al. $2001 \mathrm{a}, \mathrm{b})$ are the main predators of $O$. aculeata in this region, and other reported predators are the spider crab Hyas araneus (Bérubé 1989), the ocean pout Macrozoarces americanus (Thomas 1988) and the sunstar Crossaster papposus (Himmelman 1991). Two other important predators of ophiuroids in the western
North Atlantic, the lobster Homarus americanus (Carter \& Steel 1982, Witman 1985) and the cunner Tautogolabrus adspersus (Witman \& Sebens 1992, J. H. Himmelman pers. obs.), are absent in the Mingan Islands, probably due to the cold summer conditions caused by persistent upwelling.

Although most Ophiopholis aculeata are cryptic, we have observed individuals outside of crevices (central disk exposed) in the vicinity of the sea star Asterias vulgaris, and at times they even crawl over the aboral surface of the sea star. This usually occurs when the sea star is feeding. The presence of $A$. vulgaris does not seem to cause ophiuroids to flee, as they often extend their arms to feed within centimeters of, and even when underneath, the sea star (D. Drolet pers. obs.). As Rochette et al. (1995) and Rochette \& Himmelman (1996) observed that the whelk Buccinum undatum will at times approach its major predator (in this case the sea star Leptasterias polaris) to kleptoparasitize (steal) food in the same region (Mingan Islands), we thought that $O$. aculeata might similarly be stealing food from $A$. vulgaris. However, preliminary studies did not indicate that ophiuroids approach feeding A. vulgaris, or that ophiuroids gain food from feeding sea stars (D. Drolet unpubl. data). Studies by Gaymer et al. (2001a) on prey selection of A. vulgaris have shown that $O$. aculeata is never consumed when provided in glass aquaria (where there are no crevices), whereas sea stars readily eat ophiuroids that are tied to substratum. They speculated that the high predation rate in the field (O. aculeata accounts for $>80 \%$ of the diet of $A$. vulgaris on vertical walls) was a consequence of the cryptic behavior of ophiuroids that allowed the sea star to corner them in crevices. If this is so, exposed ophiuroids near sea stars may represent fleeing individuals, leaving crevices to avoid being captured. This would be contrary to the general rule that habitat complexity decreases prey vulnerability.

The main purpose of our study was to elucidate the apparently strange interaction between the ophiuroid Ophiopholis aculeata and the sea star Asterias vulgaris in the Mingan Islands. We first quantified the effect of sea star presence and activity (feeding and non-feeding) on the micro-distribution of ophiuroids. Secondly, we tested the counterintuitive proposal that refuge use and substratum complexity increase sea star predation on ophiuroids. We started by performing a tethering experiment in the field to evaluate the effect of substratum complexity on the vulnerability of ophiuroids to the sea star. To our surprise, we found that the urchin Strongylocentrotus droebachiensis was the main predator at our study site. We therefore included both urchins and sea stars in subsequent laboratory experiments investigating the effect of substratum complexity on the vulnerability of ophiuroids to predators. 
Finally, we compared the tendency of ophiuroids to use refuges following simulated attacks by sea stars and urchins, and linked responses of ophiuroids to the nature of the threat that predators present.

\section{MATERIALS AND METHODS}

Our study was conducted between June and August 2003 at Pointe-Enragée, in the Mingan Islands, northern Gulf of St. Lawrence, eastern Canada $\left(50^{\circ} 13^{\prime} 6^{\prime \prime} \mathrm{N}\right.$, $\left.63^{\circ} 41^{\prime} 12^{\prime \prime} \mathrm{W}\right)$. The site is an abrupt rocky cliff extending from 0 to $6 \mathrm{~m}$ in depth at the northern end, and from 10 to $20 \mathrm{~m}$ at the southern end. The wall is interrupted by narrow horizontal ledges at several locations. The cliff provides a highly complex substratum, with abundant pits in the calcareous rock and irregularities created by encrusting coralline algae (Lithothamnion sp. and Clathromorphum sp.).

The laboratory experiments were conducted in a wet laboratory at Havre Saint-Pierre, located $3 \mathrm{~km}$ from the field site, using animals collected at Pointe-Enragée by SCUBA diving. The experiments were run in tanks with flowing seawater pumped from $10 \mathrm{~m}$ depth (except when otherwise mentioned). Experimental animals were usually collected 1 to $4 \mathrm{~d}$ prior to being studied and were never collected more than $7 \mathrm{~d}$ in advance.

Reaction of ophiuroids to Asterias vulgaris in the field. To determine the impact of $A$. vulgaris on the distribution of ophiuroids, we quantified ophiuroid densities in $0.03 \mathrm{~m}^{2}$ circular areas $(20 \mathrm{~cm}$ in diameter) placed around haphazardly selected feeding $(\mathrm{N}=19)$ and non-feeding $(\mathrm{N}=39$ ) sea stars (only sea stars with 5 intact arms were studied) and also in areas where there were no sea stars within a $50 \mathrm{~cm}$ radius $(\mathrm{N}=21)$. These measurements were made on vertical walls in zones where ophiuroid densities were relatively homogeneous. We applied a 1-way ANOVA to total ophiuroid densities in the circular plots (1) with nonfeeding sea stars, (2) with feeding sea stars and (3) without sea stars.

As the preliminary analysis showed no effect of sea star presence on the density of ophiuroids in the surrounding area, we refined the observation scale by analyzing the number of ophiuroids found under the sea stars. We compared the number under each sea star (counted as we slowly lifted the sea star from the substratum) with the value expected in an area the size of the same sea star, assuming ophiuroids were evenly distributed at the density recorded in the $20 \mathrm{~cm}$ diameter plots. This value was calculated by multiplying the number of ophiuroids in the circular plot by the proportion of the area covered by the sea star. The area covered by each sea star was estimated from the rela- tion of area to radius, as previously determined from measurements of 50 sea stars (area $=1.08 x^{2}-1.21 x+$ 14.59 , where $x$ is radius, $r^{2}=0.93$; the area of these sea stars was measured from digital images using the image analysis software Sigma Scan Pro 5.0). For both non-feeding and feeding sea stars, we used paired $t$-tests to compare observed and expected values. In addition, we performed a $t$-test on the deviations from expected values to evaluate if the reactions of ophiuroids to non-feeding and feeding sea stars were different.

In the above sampling of $20 \mathrm{~cm}$ diameter plots, we also quantified the number of ophiuroids which did not have their central disk in a crevice. As the variances of these data were not homogeneous, we applied a Kruskal-Wallis $H$ test to analyze the density of exposed ophiuroids in the 3 sampling conditions (i.e. feeding sea stars, non-feeding sea stars and absence of sea stars) and we followed with Tukey's HSD post-hoc tests on the rank-transformed data.

Effect of substratum complexity on predation in the field. We performed experiments in the field with tethered ophiuroids to identify major predators and also to evaluate the effect of substratum complexity on vulnerability to predation. Ophiuroids were tethered to $28 \mathrm{~cm}$ diameter concrete plates that we set out horizontally on the ledges which interrupted the vertical wall. The surface of the plates was either smooth or complex. The complex plates (which were made to mimic the natural complexity of the wall) had two 6 to $8 \mathrm{~cm}$ long crevices (1 cm wide) and three $1.5 \mathrm{~cm}$ diameter holes (the holes and crevices were $\sim 1 \mathrm{~cm}$ deep); all crevices and holes were partly covered by pieces of coralline algae glued in place using marine epoxy. Each trial began by tethering 1 ophiuroid to a bolt in the center of a plate using a $10 \mathrm{~cm}$ long monofilament thread (8-pound test). The thread was passed through the mouth and central disk of the ophiuroid (technique adapted from Witman [1985] and Aronson [1987]) and a $5 \mathrm{~mm}$ piece of rubber was attached at the end of the thread (on the aboral face of the ophiuroid) to keep it from pulling back through the disk. We returned $6 \mathrm{~h}$ later to quantify predation. The experiment was run in 4 blocks (each during a different day on a different portion of the wall) and we ran 30 replicates in total for each of the 2 substratum types. In parallel, we ran 12 control trials in which predators were excluded by placing a cage over the plates with tethered ophiuroids. We used a semi-quantitative index to quantify predation in each trial, with 0 assigned to intact ophiuroids, 1 to those with 1 arm damaged, 2 to those with 2 or more arms damaged, 3 to those with a damaged disk and 4 to dead individuals. We analyzed the data using a mixed-model 2-way ANOVA with Block (experimental period) as the random factor and Treatment (smooth, complex and caged) as the fixed factor. 
We followed with multiple comparisons on the fixed factor using Tukey's HSD test. In all but one of the attacks (out of 32), the predator was identified because it was still feeding when we returned after $6 \mathrm{~h}$. The one case in which the predator was not observed (the ophiuroid and the rubber at the end of the thread had disappeared) was excluded from the analysis. At the end of the experiment, we sampled the experimental area (horizontal ledges interrupting vertical walls) with 25 randomly placed $0.25 \mathrm{~m}^{2}$ quadrats to quantify the density of the predators present.

Effect of substratum complexity on predation in the laboratory. We performed separate laboratory experiments to quantify the predation rates of Asterias vulgaris and Strongylocentrotus droebachiensis on ophiuroids under different levels of substratum complexity. The trials were run in plastic tanks $(45 \times 33 \times 5 \mathrm{~cm})$ with concrete bottoms with either low (smooth concrete), medium (5 crevices and 10 holes, mimicking pitted calcareous rock) or high (5 crevices and 10 holes partly covered with pieces of coralline algae, mimicking the substratum found on vertical walls) complexity (Fig. 1). Prior to each trial we placed 20 ophiuroids (6 to $13 \mathrm{~mm}$ in disk diameter) in the tank and allowed them to acclimate for at least $2 \mathrm{~h}$. We began the trial by adding the predators ( 3 sea stars or 5 sea urchins) and then made observations at 10 to $14 \mathrm{~h}$ intervals (twice daily) over a week to quantify predation. The experiments with sea stars and urchins were both run in 3 blocks (time periods) with 6 replicates of each level of substratum complexity per block. The sea stars measured 4 to $9 \mathrm{~cm}$ in radius and had been starved for a week in a 2301 pool prior to the trials, and the urchins measured 3 to $6 \mathrm{~cm}$ in test diameter and had been starved in 201 buckets for at least $2 \mathrm{~d}$ prior to the trials. We quantified predation by counting the number of ophiuroids that were eaten during each $1 \mathrm{wk}$ trial. In some cases, the outcome of an attack was not clear, as the sea star had not begun to digest the ophiuroid or the urchin had no more than 1 of the ophiuroid's arms in its mouth. These events were considered as partial attacks and were scored as 0.5. The dependent variable measured for each tank was the sum of all ophiuroids that were killed (a score of 1.0 per death) plus those that were not killed but suffered attacks (a score of 0.5 per partial attack). All ophiuroids that were attacked were removed from the tanks when they were first observed being attacked. For each predator, the intensity of predation was analyzed using a mixed-model ANOVA with Block (period of the trial) as a random factor and Substratum complexity as a fixed factor. The data for the sea star trials were log $(x+1)$-transformed to homogenize variances. Post-hoc comparisons were made with Tukey's HSD tests when a significant effect of substratum complexity was detected.

Reaction of ophiuroids to simulated attacks in the laboratory. We made laboratory trials examining the reaction of ophiuroids to the 2 predators and different levels of predatory threat. We quantified responses in a $15.5 \mathrm{~cm}$ diameter circular tank (with no inflow), which had a concrete bottom with 1 artificial refuge $(a) 1.5 \mathrm{~cm}$ diameter hole, $1 \mathrm{~cm}$ deep, partly covered with a piece of coralline algae). We first placed an ophiuroid in the tank and allowed it to crawl into the refuge. Two min

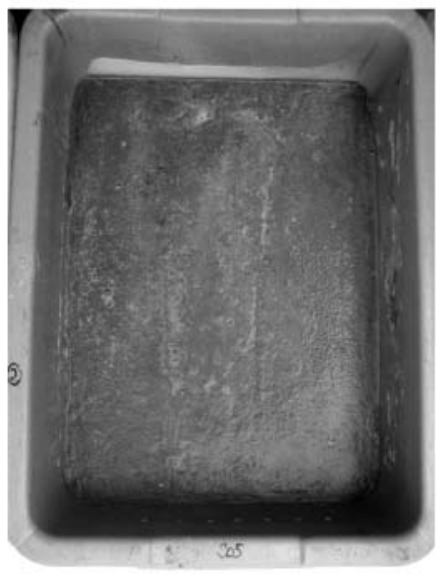

Low

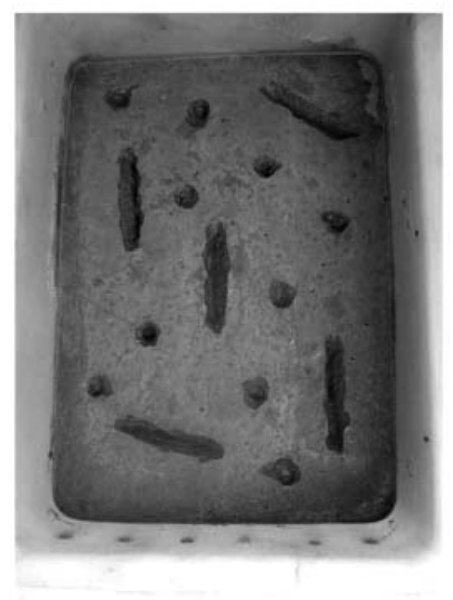

Medium

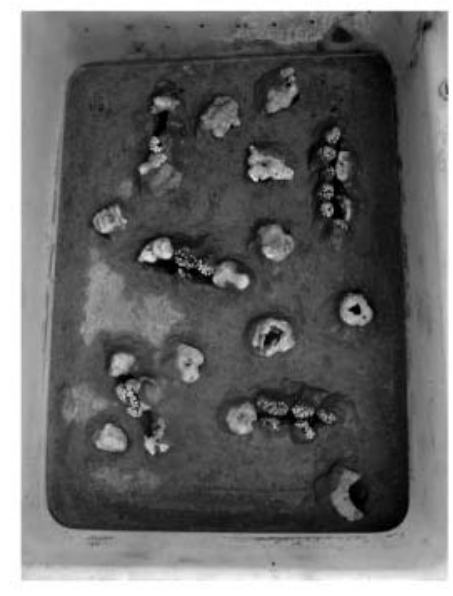

High

\section{Substratum complexity}

Fig. 1. Tanks used in the laboratory experiments investigating the effect of substratum complexity on predation, showing substrata of low, medium and high complexity 
after the ophiuroid stopped moving in the refuge, we exposed it to one of five 2 min treatments: (1) touched with a harmless object (a $7 \mathrm{~mm}$ diameter plastic pipe), as a procedural control; (2) touched with the podia and spines of a large urchin; (3) touched with the arm tip of a sea star (mimicking an approaching asteroid); (4) touched with the active podia along the ambulacral groove of a sea star (to simulate an attack); and (5) touched with a piece (mean mass $0.84 \mathrm{~g}, \mathrm{SD}=0.19$, $\mathrm{N}=4$ ) of sea star stomach (to simulate an advanced attack). As we wanted to minimize the number of sea stars sacrificed, the tests each day were performed with the stomach of 1 sea star. We made 75 trials (15 for each stimulus) in a randomized order.

Using digital photos and the image analysis software Sigma Scan Pro 5.0, we calculated the total area of each ophiuroid, and also the area exposed (outside the hole), before and after the 2 min treatment. The bottom of the tank was painted white to facilitate the analyses of the digital photos. For each trial, we then calculated the change in the exposed proportion of the ophiuroid resulting from the stimulation. A positive value meant that the ophiuroid tended to leave the crevice and a negative value that it retreated into the crevice. We analyzed the changes in exposure resulting from the different simulations using a Kruskal-Wallis $H$ test, as variances could not be made homogeneous, and followed with 2-tailed Dunnett's $t$-tests on the rank transformed data, to compare the effect of each treatment with the procedural control.

\section{RESULTS}

\section{Reaction of ophiuroids to Asterias vulgaris in the field}

Our sampling of areas without sea stars indicated that the density of ophiuroids on the vertical wall was 1460 ind. $\mathrm{m}^{-2}$, similar to the density reported by Gaymer et al. (2001a) for vertical walls elsewhere in the Mingan Islands. The densities observed in $20 \mathrm{~cm}$ diameter circular plots placed around feeding and non-feeding asteroids were virtually the same as in areas without sea stars (Fig. 2A). Thus, at this spatial scale there was no evidence that the presence of sea stars (whether feeding or not) influenced the density of ophiuroids.

Our counts of the number of ophiuroids directly under the bodies of both feeding and non-feeding sea stars were significantly lower than the expected number in an area the size of the sea star, if ophiuroids were evenly distributed at the density recorded in the $20 \mathrm{~cm}$ diameter plots $(t=5.84$, df $=38, \mathrm{p}<0.0001$ for nonfeeding sea stars; $t=8.16$, df $=18, \mathrm{p}<$ 0.0001 for feeding sea stars; Fig. 2B). In addition, the deviation from expected values was greater for feeding than for non-feeding sea stars, indicating that ophiuroids avoided the oral face of feeding sea stars to a greater extent $(t=2.97, \mathrm{df}=56, \mathrm{p}=0.004$; Fig. 2B).

The counts of exposed ophiuroids in the $20 \mathrm{~cm}$ diameter plots showed that only $0.3 \%$ ( 4.5 ind. $\mathrm{m}^{-2}$; $\mathrm{SD}=11.4$ ) were exposed in areas without sea stars. In contrast, densities of exposed ophiuroids increased 8-fold in the proximity of non-feeding Asterias vulgaris and 15 -fold in the proximity of feeding sea stars (Fig. 3). A Kruskal-Wallis test indicated that exposed ophiuroid densities varied with sea star presence and activity $\left(H_{2,79}=22.53, \mathrm{p}<0.0001\right)$ and Tukey's HSD test showed that all means were significantly different $(\mathrm{p}<$ 0.02 for all comparisons).
Fig. 2. Ophiopholis aculeata and Asterias vulgaris. (A) Field measurements of mean (+SE) density of ophiuroids in proximity of non-feeding and feeding sea stars compared with background densities (mean [solid line] \pm SE [dashed lines]). (B) Mean (+SE) number of ophiuroids found under non-feeding and feeding sea stars compared to values expected in an area the size of a sea star, if ophiuroids were evenly distributed at the density recorded in the $20 \mathrm{~cm}$ diameter plots. An asterisk indicates that a column is significantly different from the expected value. The difference between number observed and predicted value was greater when sea stars were feeding 


\section{Effect of substratum complexity on predation in the field}

Surprisingly, we only observed urchins attacking tethered ophiuroids, even though sea stars were relatively abundant and Gaymer et al. $(2001 \mathrm{a}, \mathrm{b})$ observed that ophiuroids are the preferred prey of Asterias vulgaris in the zone below shallow water mussel beds. The interaction between Block and Treatment (caged control, smooth substratum and complex substratum) was found to be non-significant $\left(F_{6,59}=1.34, \mathrm{p}=0.25\right)$ and was pooled with the error term, as suggested by Winer et al. (1991). Predation intensity varied among the 4 experimental periods $\left(F_{3,65}=3.32, \mathrm{p}=0.03\right)$ and the predation index also differed among the different treatments $\left(F_{2,65}=8.00, \mathrm{p}<0.001\right)$. Tukey's HSD multiple comparisons showed that the predation index in the caged controls was marginally smaller than that on complex substratum $(p=0.06)$ and was smaller than that on smooth substratum ( $p<0.001$; Fig. 4$)$. In fact, all 12 ophiuroids in the caged controls showed no damage, indicating that the tethers had no short-term effect on their condition. Although the predation index tended to be smaller on complex than on smooth substrata, no significant difference was found $(\mathrm{p}=0.09$; Fig. 4). Predator densities at the experimental site were 109.4 $(\mathrm{SD}=44.0)$ urchins $\mathrm{m}^{-2}$ and $3.0(\mathrm{SD}=2.9)$ sea stars $\mathrm{m}^{-2}$.

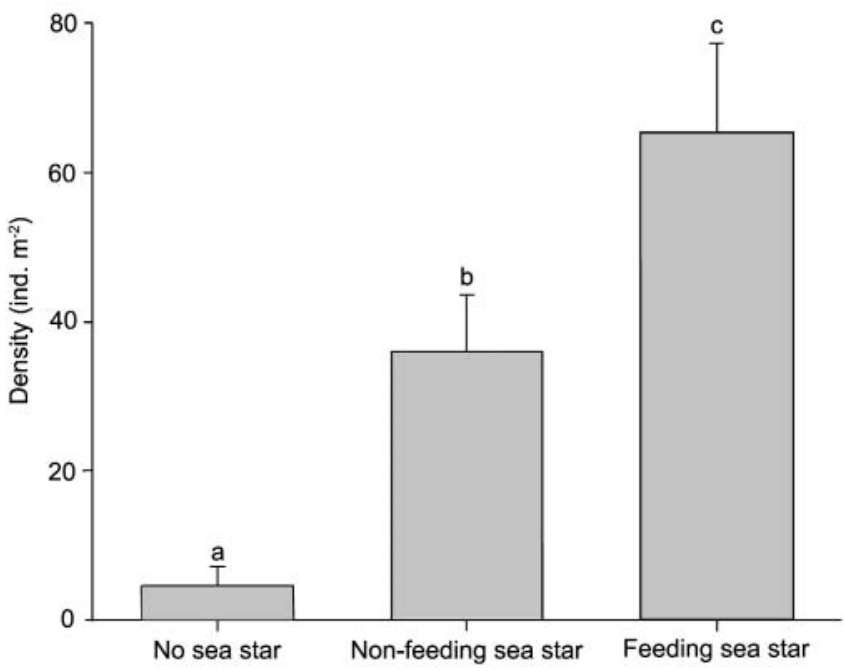

Fig. 3. Ophiopholis aculeata and Asterias vulgaris. Mean (+SE) density of exposed ophiuroids in $20 \mathrm{~cm}$ diameter circular areas where there were no sea stars and in the proximity of non-feeding and feeding sea stars. Columns not sharing a common letter are significantly different (Tukey's HSD test on the rank-transformed data, $\mathrm{p}<0.02$ for all comparisons)

\section{Effect of substratum complexity on predation in the laboratory}

When substratum complexity was low (smooth concrete) the ophiuroids tended to aggregate along the sides and in the corners of the tanks. Their behavior was similar on medium substratum complexity, except that a few ophiuroids were found in holes and crevices. Ophiuroid behavior was strikingly different when substratum complexity was high. Almost all individuals had their central disk hidden in a hole or crevice, although some arms were extended in the water column to feed. This is the usual position of ophiuroids in the field.

The full-model ANOVA applied to the logtransformed predation index for the sea stars showed no interaction between Block (period of the trial) and Substratum complexity $\left(F_{4,45}=0.21, \mathrm{p}=0.93\right)$. Thus, we used the pooled interaction and error terms to calculate F-ratios for the effects of Block and Substratum complexity, as suggested by Winer et al. (1991). The partial model revealed an effect of both Block $\left(F_{2,49}=\right.$ 9.23, $\mathrm{p}=0.0004)$ and Substratum complexity $\left(F_{2,49}=\right.$ $7.56, \mathrm{p}=0.001)$. The Block effect was probably due to water temperature increasing gradually from trial to trial, as the feeding of Asterias vulgaris increases with temperature (Gaymer et al. 2002). Tukey's HSD tests showed that the predation index was higher on the most complex substratum than on the 2 less complex substrata ( $\mathrm{p}<0.01$ for both comparisons). The predation index did not differ between low and medium substratum complexity ( $p=0.84$; Fig. 5 ).

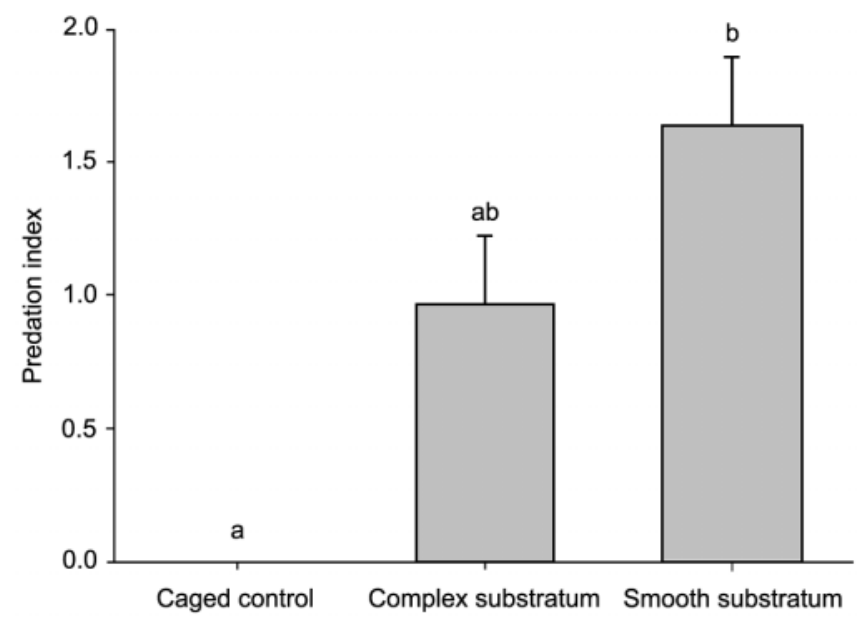

Fig. 4. Ophiopholis aculeata. Mean (+SE) predation index for ophiuroids tethered in the field on smooth and complex substrata and in cages (controls). Columns not sharing a common letter are significantly different (Tukey's HSD test) 
We again pooled the interaction and error terms when we analyzed the urchin predation data, as the interaction term in the full model was non-significant $\left(F_{4,45}=1.35, \mathrm{p}=0.27\right)$. The partial model revealed no effect of Block $\left(F_{2,49}=0.74, \mathrm{p}=0.48\right)$ and a weak effect of Substratum complexity $\left(F_{2,49}=2.44, \mathrm{p}=0.098\right)$. The pattern of predation rates observed on the different substrata was strikingly different from that observed for sea stars. Predation intensity was similar at low and medium substratum complexity and was 3 times lower at high substratum complexity (Fig. 5).

\section{Reaction of ophiuroids to simulated attacks in the laboratory}

The tendency of ophiuroids to hide in a crevice in response to different predatory and non-predatory stimuli varied markedly (Kruskal-Wallis $H_{4,69}=40.04$, p $<0.0001$; Fig. 6). Ophiuroids retracted deeper into refuges when touched with an urchin than when touched with a plastic pipe in the control treatment (Dunnett, $p=0.02$ ). In contrast, the response to being touched by the arm tip or ambulacral groove of the sea star (representing low levels of threat) was similar to the response to the control treatment (Dunnett, $\mathrm{p}=$ 0.87 and 0.84 , respectively). However, there was a great increase in exposure when touched with the stomach of the sea star (Dunnett, $\mathrm{p}<0.0001$ ). In fact, $93 \%$ of the ophiuroids tested completely left their refuge and the mean departure time was $31 \mathrm{~s}$.

\section{DISCUSSION}

Our predation experiments in both the field and laboratory indicated that substratum complexity tended to offer the ophiuroid Ophiopholis aculeata protection from predation by the urchin Strongylocentrotus droebachiensis (Figs. 4 \& 5). Although no significant effect of substratum complexity was found in either of the experiments, they both yielded similar results. In both cases, predation by urchins was less intense on the more complex substratum; thus we are confident that these tendencies represent a true effect. For practical reasons, the densities of ophiuroids and urchins in the laboratory experiment were lower than in the field (>10 times lower for ophiuroids and 3 times lower for urchins). It is likely that natural densities would increase encounter rates, and consequently enhance the effect of substratum complexity on the mortality risk of ophiuroids. The ophiuroids retracted into refuges in response to contact with the urchin (Fig. 6). This escape response, and the use of crevices in itself, should distance the ophiuroid from the urchin's feed-

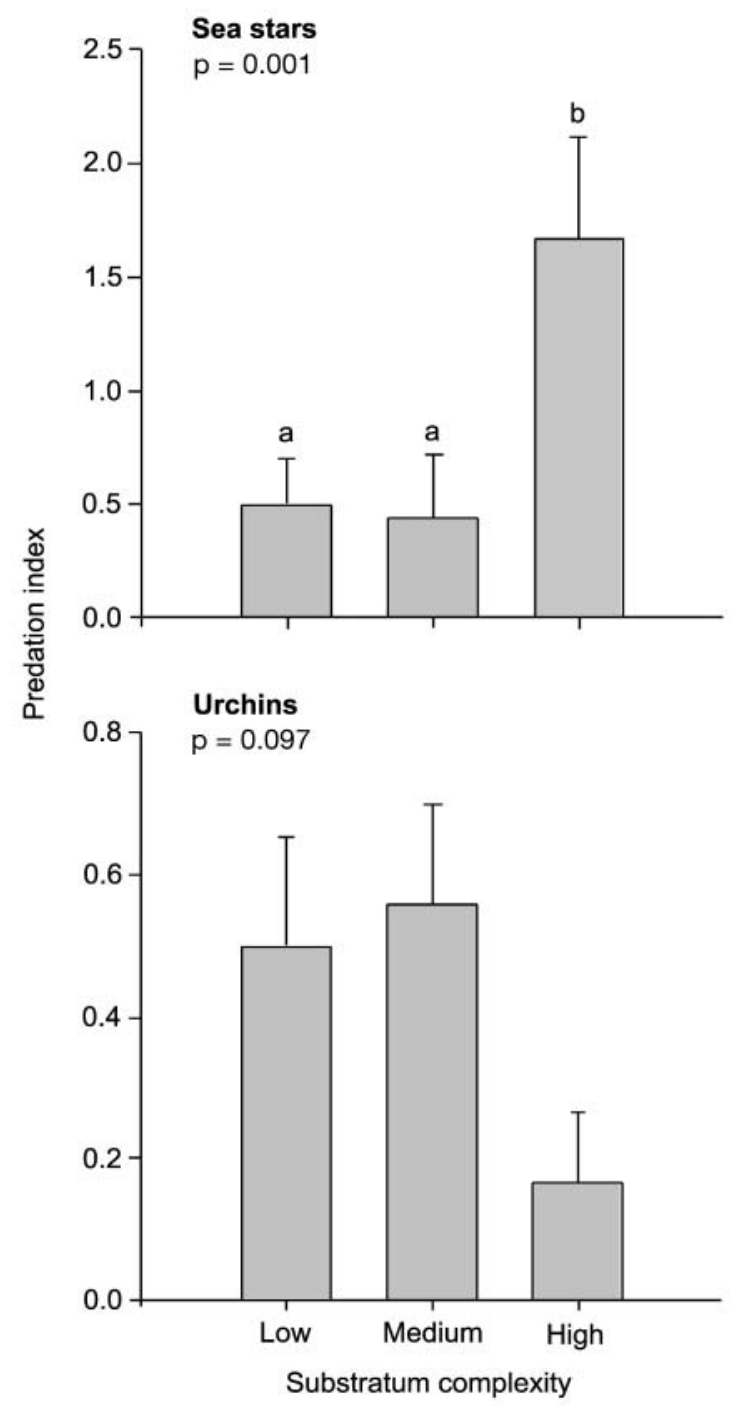

Fig. 5. Asterias vulgaris and Strongylocentrotus droebachiensis preying on Ophiopholis aculeata. Mean $(+\mathrm{SE})$ predation index in laboratory experiments on substrata with low, medium and high complexity. p-values are for the substratum complexity factor in partial mixed-model ANOVAs, in which the interaction term was pooled with the error term. Predation indices for sea stars were log-transformed prior to the analysis and back-transformed for presentation. In the upper panel, columns not sharing a common letter are significantly different (Tukey's HSD)

ing apparatus. Our observations of the interaction between the ophiuroid and the urchin corroborate the hypothesis that habitat complexity provides protection from predation (see references in 'Introduction'). Algae are the main food of sea urchins, and their intensive grazing limits the distribution of most fleshy macroalgae (Himmelman et al. 1983). However, the urchin also consumes animals when available and accessible (Himmelman \& Steel 1971, Briscoe \& Sebens 1988). Our experiments show that $S$. droe- 


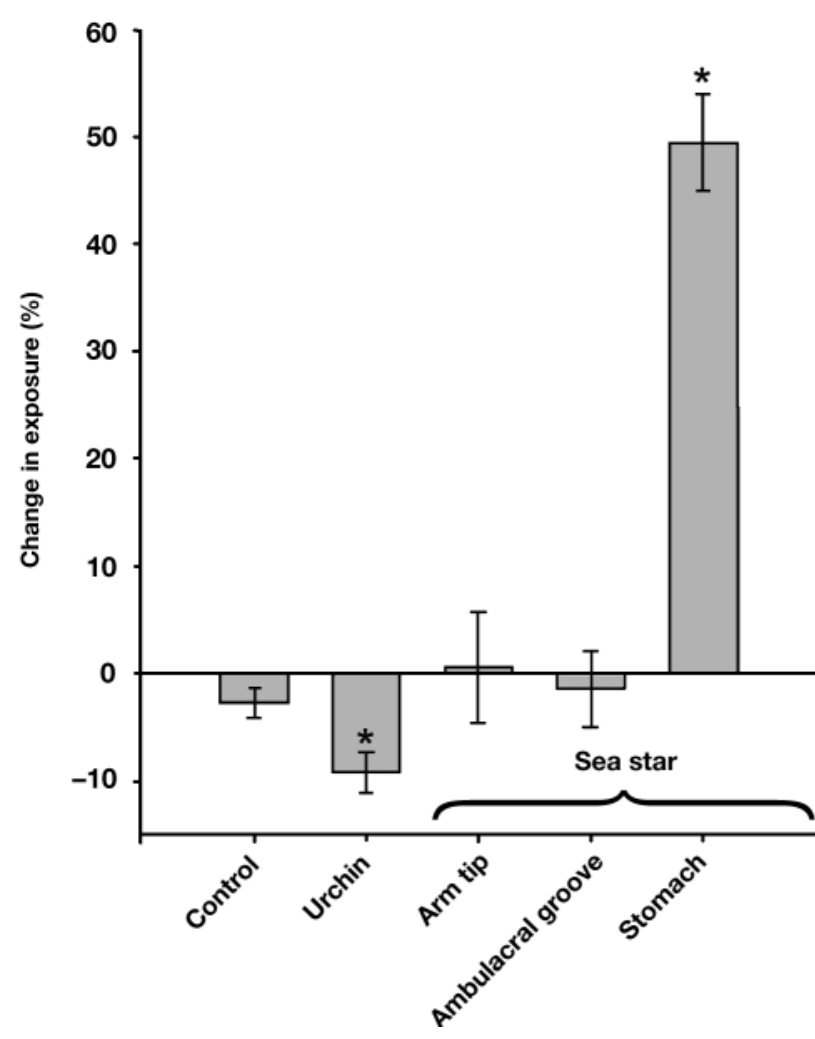

Fig. 6. Asterias vulgaris and Strongylocentrotus droebachiensis attacks on Ophiopholis aculeata. Mean $( \pm \mathrm{SE})$ change in body exposure for ophiuroids following simulated attacks by the urchin and different threats posed by the sea star. An asterisk indicates a significant difference from the procedural control (Dunnett's $t$-test on the rank transformed data)

bachiensis feeds on ophiuroids, as noted in an early report by Blegvad (1914). In fact, ophiuroids appear to be a common food item of urchins on vertical walls in the Mingan Islands as ophiuroids were found in the guts of $26 \%$ of urchins $(\mathrm{N}=53$ ) collected at PointeEnragée in August 2002 (D. Drolet unpubl. data).

In contrast to urchins, predation by sea stars on ophiuroids increased with substratum complexity (Fig. 5). Following encounter, prey escape probability is usually enhanced in complex habitats, as structural components may reduce either the predator's maneuverability or access to prey (Ryer 1988, Bartholomew et al. 2000). Although contrary to this general rule, our results make sense if we consider the biology of the organisms involved. Asterias vulgaris moves slowly and can easily be outrun by the ophiuroid on smooth substratum (Gaymer et al. 2001a). However, substratum complexity may interfere with the displacement of ophiuroids. In addition, the movement of the sea star does not seem to be limited by the degree of substratum complexity, at least with the arrangement of structural components used in our experiments which was meant to mimic the substratum at our field site (i.e. pitted calcareous rock covered by encrusting coralline algae). On the contrary, it appears that ophiuroids can be trapped in crevices in calcareous rock and coralline algae. The soft body of the sea star likely allows it to block the departure of an ophiuroid from a crevice, into which it can then readily evert its stomach and digest its prey. Bartholomew et al. (2000) proposed that the ratio of spacing of structural components in a habitat to the width of a predator can be used as a predictor of predation rates. However, our results indicate that predation rates may be more accurately predicted by considering the relative effect of structural complexity on displacement of both predator and prey. We predict that habitat complexity should increase predation when the movement of the prey is more limited by structural components than that of the predator.

Tethering experiments are criticized because experimental artifacts may differ between treatments. For example, using tethering to evaluate predation rates in different habitats is often biased if predator guilds vary with habitat (Peterson \& Black 1994, Haywood et al. 2003), as tethering artifacts can vary with different predators (Barbeau \& Scheibling 1994). Our trials were not subjected to this bias, as we placed the artificial substrata in the same habitat at a single location. In addition, only urchins were observed attacking tethered ophiuroids. We cannot exclude the possibility that the tethers restricted the movement of ophiuroids more on one substratum than another, or that they facilitated attacks by one predator (e.g. the urchin) more than those by others. Thus, we cannot definitively conclude that predation by urchins is more important than predation by sea stars, although our results strongly suggest that it this the case.

In the laboratory, ophiuroids displayed strong threatsensitivity to Asterias vulgaris. They reacted weakly to the arm tip and ambulacral groove, which represented low and medium levels of threat, respectively, but they showed a violent reaction to the sea star's stomach (Fig. 6). Since ophiuroids in crevices are at greater risk of being preyed upon by the sea star, fleeing from crevices may reduce the probability of capture following encounter. It has been shown that many prey species of sea stars react to the presence of their predator through the detection of asterosaponins (molecules exuded by many sea star species) (Harvey et al. 1987) and that these molecules are most concentrated in stomach tissues (Garneau et al. 1989). The strong response to the stomach of $A$. vulgaris might be due to a higher concentration of asterosaponins. Concentrations exuded by arm tips and ambulacral grooves appear to be too low to elicit flight, although it is also possible that ophiuroids discriminate chemicals present in different tissues. 
We first became interested in the interaction between Ophiopholis aculeata and Asterias vulgaris after observing ophiuroids on the top of the sea star. This was surprising given that the ophiuroid is the main prey of $A$. vulgaris in this community. Our initial hypothesis was that the ophiuroid might approach the feeding sea star to kleptoparasitize food. Our sampling in $20 \mathrm{~cm}$ circular areas showed that the density of the ophiuroid did not change with the presence or absence of the sea star, or if the sea star was feeding or not (Fig. 2A). This suggests that ophiuroids do not move toward sea stars. Our sampling of ophiuroids directly under the body of the sea star revealed that densities were less than on equivalent surfaces without sea stars, and further that densities were less under feeding than non-feeding sea stars (Fig. 2B). The reduction in the number of ophiuroids under feeding sea stars is probably a consequence of the fleeing of ophiuroids that came into contact with the stomach, as observed in the laboratory simulations. However, the explanation for the reduction under non-feeding sea stars is unclear, as ophiuroids in the laboratory did not react to contact with the arm tip and ambulacral groove of A. vulgaris. Possibly the duration of the laboratory simulations (2 $\mathrm{min}$ ) was too short to elicit a reaction. In parallel, we documented a strong increase in densities of exposed individuals near $A$. vulgaris in comparison to areas without sea stars, and exposed ophiuroids were most abundant near feeding sea stars (Fig. 3). The exposed individuals probably represented fleeing individuals, as the escape response of ophiuroids to the sea star in the laboratory was to flee from crevices. These observations suggest that ophiuroids do react to their sea star predator, although only by moving a few centimeters. A proportion of these fleeing ophiuroids likely climb onto the aboral surface of the sea stars, which should be a low risk location. Thus, the peculiar observation of ophiuroids on top of sea stars does not represent individuals drawn to sea stars for feeding opportunities, but rather ophiuroids fleeing to escape being eaten.

The strong threat-sensitivity of Ophiopholis aculeata to its sea star predator (not fleeing until the last moment) probably represents a trade-off between predation risk from the sea star and other predators. Although delayed departure from crevices probably increases the capture probability by the sea star, it minimizes time spent on open surfaces, where the ophiuroid is vulnerable to urchins and perhaps other predators. These behavioral responses to the 2 predators should minimize the overall probability of mortality. This hypothesis needs to be tested in experiments with combinations of both predators. We predict that the presence of Asterias vulgaris will indirectly increase the predation efficiency of urchins by increas- ing the number of exposed ophiuroids. Studies are also needed to investigate changes in the behavior of the ophiuroid in warmer North Atlantic areas, where other ophiuroid predators, notably fish and decapod crustaceans, are abundant (Witman 1985, Witman \& Sebens 1992).

Acknowledgements. We are grateful to D. Aeillo, I. Deschênes, S.-P. Gingras, P. Grondin, M. Nadon, F. Praira, $\mathrm{M}$. Thompson and C.Vallières, who assisted this work in the field and the laboratory. Special thanks to C. Dumont for many good suggestions during the course of the project and to H. Feder and L. Johnson for suggestions on improving the manuscript. This research was financed by a NSERC operating grant to J.H.H.

\section{LITERATURE CITED}

Aronson RB (1987) Predation of fossil and recent ophiuroids. Paleobiology 13:187-192

Arsenault DJ, Himmelman JH (1996) Size-related changes in vulnerability to predators and spatial refuge use by juvenile Iceland scallops Chlamys islandica. Mar Ecol Prog Ser 140:115-122

Barbeau MA, Scheibling RE (1994) Procedural effects of prey tethering experiments: predation of juvenile scallops by crabs and sea stars. Mar Ecol Prog Ser 111:305-310

Bartholomew A, Diaz RJ, Cicchetti G (2000) New dimensionless indices of structural habitat complexity: predicted and actual effects on a predator's foraging success. Mar Ecol Prog Ser 206:45-58

Behrens Yamada S, Navarrete SA, Needham C (1998) Predation induced changes in behavior and growth rate in three populations of the intertidal snail, Littorina sitkana (Philippi). J Exp Mar Biol Ecol 220:213-226

Bérubé M (1989) Partage des ressources entre le crabe tourteau, Cancer irroratus Say, et le crabe araignée Hyas araneus Linnee, au nord du Golfe du Saint-Laurent. MSc thesis, Université Laval, Sainte-Foy, Québec

Beukers JS, Jones GP (1997) Habitat complexity modifies the impact of piscivores on a coral reef fish population. Oecologia 114:50-59

Bishop TD, Brown JA (1992) Threat-sensitive foraging by larval threespine sticklebacks (Gasterosteus aculeatus). Behav Ecol Sociobiol 31:133-138

Blevgad H (1914) Food and conditions of nourishment among the invertebrate animals in or on the sea bottom in Danish waters. Rep Dan Biol St 22:42-78

Briscoe CS, Sebens KP (1988) Omnivory in Strongylocentrotus droebachiensis (Müller) (Echinodermata: Echinoidea): predation on subtidal mussels. J Exp Mar Biol Ecol 115: $1-24$

Brokordt KB, Guderley HE, Gay M, Gaymer CF, Himmelman JH (2003) Sex difference in reproductive investment: maternal care reduces escape response capacity in the whelk, Buccinum undatum. J Exp Mar Biol Ecol 291:161-180

Brun E (1972) Food and feeding habits of Luidia ciliaris (Echinodermata: Asteroidea). J Mar Biol Assoc UK 52: $225-236$

Carter JA, Steel DH (1982) Stomach contents of immature lobsters (Homarus americanus) from Placentia Bay, Newfoundland. Can J Zool 60:337-347

Coull BC, Wells JBJ (1983) Refuges from fish predation: experiments with phytal meiofauna from the New Zealand rocky intertidal. Ecology 64:1599-1609 
Deheyn D, Mallefet J, Jangoux M (2000) Expression of bioluminescence in Amphipholis squamata (Ophiuroidea: Echinodermata) in presence of various organisms: a laboratory study. J Mar Biol Assoc UK 80:179-180

Diehl S (1988) Foraging efficiency of three freshwater fishes: effects of structural complexity and light. Oikos 53: 207-214

Eklov P (1997) Effects of habitat complexity and prey abundance on the spatial and temporal distributions of perch (Perca fluviatilis) and pike (Esox lucius). Can J Fish Aquat Sci 54:1520-1531

Feder HM, Arvidsson J (1967) Studies on a sea-star (Marthasterias glacialis) extract responsible for avoidance reactions in a gastropod (Buccinum undatum). Ark Zool 19: 369-379

Flynn AJ, Ritz DA (1999) Effect of habitat complexity and predatory style on the capture success of fish feeding on aggregated prey. J Mar Biol Assoc UK 79:487-494

Fontaine AR (1964) The integumentary mucous secretions of the ophiuroid Ophiocomina nigra. J Mar Biol Assoc UK 44: 145-162

Fraser DF, Gilliam JF (1987) Feeding under predation hazard: response of the guppy and Hart's rivulus from sites with contrasting predation hazard. Behav Ecol Sociobiol 21: 203-209

Garneau FX, Harvey C, Simard, JL, ApSimon JW, Burnell DJ, Himmelman JH (1989) The distribution of asterosaponins in various body components of the starfish Leptasterias polaris. J Comp Physiol B 92:411-416

Gaymer CF, Himmelman JH, Johnson LE (2001a) Use of prey resources by the seastars Leptasterias polaris and Asterias vulgaris: a comparison between field observations and laboratory experiments. J Exp Mar Biol Ecol 262:13-30

Gaymer CF, Himmelman JH, Johnson LE (2001b) Distribution and feeding ecology of the seastars Leptasterias polaris and Asterias vulgaris in the northern Gulf of St Lawrence, Canada. J Mar Biol Assoc UK 81:827-843

Gaymer CF, Himmelman JH, Johnson LE (2002) Effect of intra- and interspecific interactions on the feeding behavior of two subtidal sea stars. Mar Ecol Prog Ser 232: 149-162

Gosselin LA, Chia FS (1995) Distribution and dispersal of early juvenile snails: effectiveness of intertidal microhabitats as refuges and food sources. Mar Ecol Prog Ser 128: 213-223

Grober MS (1988a) Brittle-star bioluminescence functions as an aposematic signal to deter crustacean predators. Anim Behav 36:493-501

Grober MS (1988b) Response of tropical reef fauna to brittlestar luminescence (Echinodermata: Ophiuroidea). J Exp Mar Biol Ecol 115:157-168

Harvey C, Garneau FX, Himmelman JH (1987) Chemodetection of the predatory seastar Leptasterias polaris by the whelk Buccinum undatum. Mar Ecol Prog Ser 40:79-86

Haywood MDE, Manson FJ, Loneragan NR, Toscas PJ (2003) Investigation of artifacts from chronographic tethering experiments - interactions between tethers and predators. J Exp Mar Biol Ecol 290:271-292

Helfman GS (1989) Threat-sensitive predator avoidance in damselfish-trumpetfish interactions. Behav Ecol Sociobiol $24: 47-58$

Hendler G (1984) Brittlestar color-change and phototaxis (Echinodermata: Ophiuroidea: Ophoicomidae). PSZN I: Mar Ecol 5:379-401

Himmelman JH (1991) Diving observations of subtidal communities in the northern Gulf of St. Lawrence. In: Therriault JC (ed) The Gulf of St. Lawrence, small ocean or big estuary. Can Spec Publ Fish Aqut 113:319-332

Himmelman JH, Steel DH (1971) Foods and predators of the green sea urchin Strongylocentrotus droebachiensis in Newfoundland waters. Mar Biol 9:315-322

Himmelman JH, Cardinal A, Bourget E (1983) Community development following removal of urchins, Strongylocentrotus droebachiensis, from the rocky subtidal zone of the St. Lawrence Estuary, eastern Canada. Oecologia 59: 27-39

James PL, Heck KL (1994) The effects of habitat complexity and light intensity on ambush predation within a simulated seagrass habitat. J Exp Mar Biol Ecol 176:187-200

Johns PM, Mann KH (1987) An experimental investigation of juvenile lobster habitat preference and mortality among habitats of varying structural complexity. J Exp Mar Biol Ecol 109:275-285

Jones KMM, Boulding EG (1999) State-dependant habitat selection by an intertidal snail: the costs of selecting a physically stressful microhabitat. J Exp Mar Biol Ecol 242: 149-177

Keats DW, Steel DH, South GR (1987) Ocean pout (Macrozoarces americanus (Bloch and Schneider) (Pisces: Zoarcidea)) predation on green sea urchins (Strongylocentrotus droebachiensis (O.F. Müll.) (Echinodermata: Echimoidea)) in eastern Newfoundland. Can J Zool 65: 1515-1521

Kenyon RA, Loneragan NR, Hughes JM (1995) Habitat type and light affect sheltering behaviour of juvenile tiger prawns (Penaeus esculentus Haswell) and success rates of their fish predator. J Exp Mar Biol Ecol 192:87-105

LaBarbera M (1978) Particle capture by a Pacific brittle star: experimental test of the aerosol suspension feeding model. Science 201:1147-1149

Legault C, Himmelman JH (1993) Relation between escape behavior of benthic marine invertebrates and the risk of predation. J Exp Mar Biol Ecol 170:55-74

Lemire M, Bourget E (1996) Substratum heterogeneity and complexity influence micro-habitat selection of Balanus sp. and Tubularia crocea larvae. Mar Ecol Prog Ser 135: 77-87

Levitan DR, Genovese SJ (1989) Substratum-dependent predator-prey dynamics: patch reefs as refuges from gastropod predation. J Exp Mar Biol Ecol 130:111-118

Lima SL, Dill LM (1990) Behavioral decisions made under the risk of predation: a review and prospectus. Can J Zool 68: 619-640

Main KL (1987) Predator avoidance in seagrass meadows: prey behavior, microhabitat selection, and cryptic coloration. Ecology 68:170-180

Moksnes PO, Pihl L, van Montfrans J (1998) Predation on postlarvea and juveniles of the shore crab Carcinus maenas: importance of shelter, size and cannibalism. Mar Ecol Prog Ser 166:211-225

Moran PJ, Reaka ML (1988) Bioerosion and availability of shelter for benthic reef organisms. Mar Ecol Prog Ser 44: 249-263

Nelson WG, Bonsdorff E (1990) Fish predation and habitat complexity: are complexity tresholds real? J Exp Mar Biol Ecol 141:183-194

Nemeth RS (1998) The effect of natural variation in substrate architecture on the survival of juvenile bicolor damselfish. Environ Biol Fish 53:129-141

Packer DB, Watling L, Langton RW (1994) The population structure of the brittle star Ophiura sarsi Lunkten in the Gulf of Maine and its trophic relationship to American plaice (Hippoglossoides platessoides Fabricius). J Exp Mar Biol Ecol 179:207-222 
Peterson CH, Black R (1994) An experimentalist's challenge, when artifacts of intervention interact with treatments. Mar Ecol Prog Ser 111:289-297

Rochette R, Himmelman JH (1996) Does vulnerability influence trade-offs made by whelks between predation risk and feeding opportunities? Anim Behav 52:783-794

Rochette R, Morissette S, Himmelman JH (1995) A flexible response to a major predator provides the whelk Buccinum undatum L. with nutritional gains. J Exp Mar Biol Ecol 185:167-180

Rosenberg R, Selander E (2000) Alarm signal response in the brittle star Amphiura filiformis. Mar Biol 136:43-48

Russo AR (1987) Role of habitat complexity in mediating predation by the gray damselfish Abudefduf sordidus on epiphytal amphipods. Mar Ecol Prog Ser 36:101-105

Ryer CH (1988) Pipiefish foraging: effects of fish size, prey size and altered habitat complexity. Mar Ecol Prog Ser 48: $37-45$

Skold M (1998) Escape responses in four epibenthic brittle stars (Ophiuroidea: Echinodermata). Ophelia 49:163-179

Solan M, Battle EJV (2003) Does the ophiuroid Amphiura filiformis alert conspecifics to the danger of predation through the generation of an alarm signal? J Mar Biol Assoc UK 83:1117-1118

Sponaugle S, Lawton P (1990) Portunid crab predation on juvenile hard clams: effects of substrate type and prey density. Mar Ecol Prog Ser 67:43-53

Steger R (1987) Effects of refuges and recruitment on Gonodactylid Stomatopods, a guild of mobile prey. Ecology 68: $1520-1533$

Stunz GW, Minello TJ (2001) Habitat-related predation on juvenile wild-caught and hatchery-reared red drum Sciaenops ocellatus (Linnaeus). J Exp Mar Biol Ecol 260: $13-25$

Thomas B (1988) L'utilisation des ressources infralittorales par une communauté de poissons démersaux. MSc thesis, Université Laval, Sainte-Foy, Québec

Editorial responsibility: Roger Hughes (Contributing Editor), Bangor, UK
Vadas RL, Burrows MT, Hughes RN (1994) Foraging strategies of dogwhelks, Nucella lapillus (L.): interacting effects of age, diet and chemical cues to the threat of predation. Oecologia 100:439-450

Wahle RA, Steneck RS (1992) Habitat restrictions in early benthic life: experiments on habitat selection and in situ predation with the American lobster. J Exp Mar Biol Ecol 157:91-114

Walsh EJ (1995) Habitat-specific predation susceptibilies of a littoral rotifer to two invertebrate predators. Hydrobiologia 313/314:205-211

Walters LJ, Wethey DS (1996) Settlement and early postsettlement survival of sessile marine invertebrates on topographically complex surfaces: the importance of refuge dimensions and adult morphology. Mar Ecol Prog Ser 137:161-171

Wilkie IC (1978) Arm autotomy in brittlestars (Echinodermata: Ophiuroidea). J Zool 186:311-330

Winer BJ, Brown DR, Michels KM (1991) Statistical principles in experimental design. McGraw-Hill, New York

Witman JD (1985) Refuges, biological disturbance, and rocky subtidal community structure in New England. Ecol Monogr 55:421-445

Witman JD, Sebens KP (1992) Regional variation in fish predation intensity: a historical perspective in the Gulf of Maine. Oecologia 90:305-315

Wong MC, Barbeau MA (2003) Effects of substrate on interactions between juvenile sea scallops (Placopecten magellanicus Gmelin) and predatory sea stars (Asterias vulgaris Verrill) and rock crabs (Cancer irroratus Say). J Exp Mar Biol Ecol 287:155-178

Wurzian RS (1977) Predator-prey interaction between the crab Pilumnus hirtellus (Leach) and the brittle star Ophiothrix quinquemaculata (D. chiaje) on a mutual sponge substrate. In: Keegan BF, Ceidigh PO, Boaden PJS (eds) Biology of benthic organisms, 11th Eur Mar Biol Symp, Galway, October 1976. Pergamon Press, Oxford, p 613-620

Submitted: March 28, 2004; Accepted: July 19, 2004

Proofs received from author(s): December 1, 2004 